\title{
Sibling Sex Ratio and Birth Order in Early-Onset Gender Dysphoric Adolescents
}

\author{
Sebastian E. E. Schagen - Henriette A. Delemarre-van de Waal • \\ Ray Blanchard $\cdot$ Peggy T. Cohen-Kettenis
}

Received: 28 June 2010/Revised: 16 April 2011 / Accepted: 30 April 2011 / Published online: 15 June 2011

(C) The Author(s) 2011. This article is published with open access at Springerlink.com

\begin{abstract}
Several sibship-related variables have been studied extensively in sexual orientation research, especially in men. Sibling sex ratio refers to the ratio of brothers to sisters in the aggregate sibships of a group of probands. Birth order refers to the probands' position (e.g., first-born, middle-born, last-born) within their sibships. Fraternal birth order refers to their position among male siblings only. Such research was extended in this study to a large group of early-onset gender dysphoric adolescents. The probands comprised 94 male-to-female and 95 female-to-male gender dysphoric adolescents. The overwhelming majority of these were homosexual or probably prehomosexual. The control group consisted of 875 boys and 914 girls from the TRAILS study. The sibling sex ratio of the gender dysphoric boys was very high (241 brothers per 100 sisters) compared with the expected ratio (106:100). The excess of brothers was more extreme among the probands' older siblings (300: $100)$ than among their younger siblings (195:100). Betweengroups comparisons showed that the gender dysphoric boys had significantly more older brothers, and significantly fewer
\end{abstract}

S. E. E. Schagen · H. A. Delemarre-van de Waal

Department of Pediatric Endocrinology, VU University Medical

Centre, Amsterdam, The Netherlands

H. A. Delemarre-van de Waal

Department of Pediatrics, LUMC University Hospital Leiden,

Leiden, The Netherlands

R. Blanchard

Law and Mental Health Program, Centre for Addiction and Mental

Health, Toronto, ON, Canada

P. T. Cohen-Kettenis $(\square)$

Department of Medical Psychology and Medical Social Work, VU

University Medical Centre, PO Box 7057, 1007 MB Amsterdam,

The Netherlands

e-mail: PT.Cohen-Kettenis@vumc.nl older sisters and younger sisters, than did the control boys. In contrast, the only notable finding for the female groups was that the gender dysphoric girls had significantly fewer total siblings than did the control girls. The results for the male probands were consistent with prior speculations that a high fraternal birth order (i.e., an excess of older brothers) is found in all homosexual male groups, but an elevated sibling sex ratio (usually caused by an additional, smaller excess of younger brothers) is characteristic of gender dysphoric homosexual males. The mechanisms underlying these phenomena remain unknown.

Keywords Birth order - Sibling sex ratio . Gender identity disorder - Gender dysphoria . Homosexuality · Transsexualism

\section{Introduction}

The ratio of brothers to sisters reported by a defined group of probands is known as the "sibling sex ratio." In most Western societies, the secondary sex ratio - the sex ratio at birth-is relatively constant (Chahnazarian, 1988). In a Western country, the ratio of brothers to sisters in a randomly chosen group should be approximately 106:100 (Chahnazarian, 1988; James, 1987). The sibling sex ratio has often been investigated in studies on sexual orientation in men. An increased number of brothers in comparison to the number of sisters in a group of homosexual men was first found by Lang (1960). Since that study, the relation between sexual orientation and sibling sex ratio has been studied in many other groups. Blanchard (1997) reviewed the data of all studies until 1997 on sibling sex ratio and homosexuality. His findings suggested that only the extremely feminine homosexual male groups had a high sibling sex ratio.

Another biodemographic variable that seems to be related to the development of a homosexual sexual orientation is birth 
order. Birth order represents the position of a proband in his or her family (e.g., last or first born). Slater (1958) introduced a method for quantifying birth order, the so-called Slater's Index. This index is calculated by dividing the number of older siblings by the total number of siblings.

The birth order in relation to sisters only is called the "sororal birth order." With regard to brothers, it is called the "fraternal birth order." It has been calculated for males that each additional older brother increases the odds of the proband being homosexual by as much as 33-40\% (Blanchard \& Bogaert, 1996; Green, 2000). In males, having older sisters does not influence these odds; that is why this phenomenon is called the fraternal birth order effect (Blanchard, 1997, 2001; Blanchard \& Lippa, 2007; Bogaert, 2006; Green, 2000). In females, no class of siblings has been found to be associated with sexual orientation (Bogaert \& Cairney, 2004; Green, 2000).

The exact mechanism underlying the fraternal birth order effect is still unclear. Bogaert (2006) showed that only the number of biological brothers increased the odds of homosexuality in later-born males. These results suggest a biological origin for the effect, rather than an environmental effect, such as rearing. Other research also seems to indicate a more biological etiology for the fraternal birth order effect. For instance, Blanchard et al. (2002) found a lower birth weight in probably prehomosexual feminine boys compared to probably pre-heterosexual boys. Also, homosexual males seem to be shorter relative to heterosexual males (Bogaert \& Liu, 2006). In both examples, the effect is more pronounced with the presence of more older brothers.

The most commonly used explanation for the fraternal birth order effect is the maternal immune hypothesis (Blanchard, 2001, 2008; Blanchard \& Klassen, 1997). Some mothers may develop a progressive immunization to Y-linked minor histocompatibility antigens, the so-called H-Y antigens. This is comparable to the rhesus immunization in which a mother who is rhesus negative will develop antibodies against the rhesus positive blood cells of her unborn child. The immune reaction of the mother will become stronger at each following pregnancy of a rhesus positive child. However, the maternal immune hypothesis would only be applicable to the male offspring; thus, the clinical example of rhesus blood group incompatibility is not completely applicable.

The question arises whether these two variables reported to differentiate homosexual from non-homosexual men also differentiate gender dysphoric individuals (also called transsexuals or individuals with gender identity disorder [GID]) from nongender dysphoric individuals. To our knowledge, 12 studies have investigated birth order and/or sibling sex ratio among gender dysphoric individuals (or their closest equivalents in non-Western cultures). Nine of these studies looked at differences in birth order and sibling sex ratio between "homosexual" and "nonhomosexual" transsexual adults (Blanchard \& Sheridan, 1992; Blanchard, Zucker, Cohen-Kettenis, Gooren, \& Bailey, 1996; Gomez-Gil et al., 2011; Green, 2000; Poasa, Blanchard, \& Zucker, 2004; Tsoi, Kok, \& Long, 1977; VanderLaan \& Vasey,
2011; Vasey \& VanderLaan, 2007; Zucker, Blanchard, Kim, Pae, \& Lee, 2007) (instead of "homosexual" transsexuals, we will refer to male-to-female transsexuals sexually attracted to men as androphilic MtFs, and to female-to-male transsexuals sexually attracted to women as gynephilic FtMs). Overall, these studies found an excess of brothers in the androphilic MtFs groups but not in the non-androphilic transsexual male groups. Only one study on androphilic MtFs found an excess of sisters instead of brothers, but this may have been a consequence of the male-preference stopping rule that is active in South Korea (Zucker et al., 2007). In natal females, Green (2000) found that gynephilic FtMs had more sisters than brothers, but Blanchard and Sheridan (1992) did not find a significant excess of sisters in their group of gynephilic FtMs.

With regard to birth order, it was found that androphilic MtFs were significantly later born in comparison to the control groups, especially with regard to their brothers (Blanchard \& Sheridan, 1992; Blanchard et al., 1996; Green, 2000). Zucker et al. (2007) also found a later than average birth order in a South Korean sample, but this did not significantly differ from the control group. Poasa et al. (2004) found that androphilic MtFs were born later in comparison to their brothers and sisters, but the effect seemed to be somewhat stronger with regard to their older brothers.

Of these studies, three reported on data of young gender dysphoric individuals (Blanchard et al., 1996; Zucker et al., 1997; Zucker, Lightbody, Pecore, Bradley, \& Blanchard, 1998). Blanchard et al. found a significant later than average birth order for 21 androphilic $\mathrm{MtF}$ adolescents in comparison to 21 control male subjects. In Zucker et al. (1997), the fraternal and sororal birth order as well as the sibling sex ratio were examined in 333 prepubertal boys diagnosed with a GID. In this study, the probands appeared to be born later relative to their brothers than they were to their sisters. The sibling sex ratio showed an excess of brothers.

In prepubertal gender dysphoric girls, only birth order has been examined (Zucker et al., 1998). In a small sample of 22 gender dysphoric girls and 147 control girls, the gender dysphoric girls were significantly more likely to be early born, especially in relation to their sisters but not their brothers. This is the opposite of what was found in homosexuals and androphilic MtFs.

We were able to study a substantial group of peripubertal gender dysphoric children and adolescents who had been gender dysphoric since childhood and were considered to have earlyonset gender dysphoria (Smith, van Goozen, Kuiper, \& CohenKettenis, 2005). Based on the literature, we hypothesized that, in this group of early-onset, probably predominantly androphilic $\mathrm{MtF}$, we would find a higher sibling sex ratio, a later birth order, and more older brothers than the biological males in the control group. For the early-onset, probably predominantly gynephilic FtMs, we hypothesized that they would have a lower sibling sex ratio, an earlier birth order, and more younger sisters than the biological girls in the control group. 


\section{Method}

Participants

The probands were 94 biologically male and 95 biologically female, peripubertal gender dysphoric patients who attended the Gender Identity Clinic for children and adolescents of the VU University Medical Center between 1997 and 2008. Of these, 74 boys ( $\mathrm{M}$ age 13.4 years; range, 9.0-17.7) and 85 girls (M age 13.6 years; range, 9.1-17.9) met the complete DSM-IV-TR (American Psychiatric Association, 2000) criteria for GID. The remaining 20 boys ( $\mathrm{M}$ age, 12.6 years; range, 9.2-17.8) and 10 girls (M age, 12.8 years; range, 9.0-17.0) were subthreshold for the diagnosis but showed a number of indicators of GID. Data on date of birth, number and age of siblings, data on biological relation, and nationality were available for all patients.

The control subjects were participants of the TRacking Adolescents' Individual Lives Survey (TRAILS) study (De Winter et al., 2005). In this prospective cohort study, a large number of Dutch preadolescents are being followed until they are 24 years old. For sampling procedures, see De Winter et al. (2005). The key objective of TRAILS was to chart and explain the development of mental health from preadolescence into adulthood, both at the level of psychopathology and the levels of underlying vulnerability and environmental risk. The TRAILS data file consisted of 2230 adolescents (M age, 11.09 years; $50.8 \%$ girls). Of this group, date of birth, number and age of siblings, data on biological relation, and nationality were also available. All participants with a non-Dutch nationality $(n=$ $235)$ and with an incomplete dataset $(n=206)$ were excluded. The remaining 1789 adolescents were enrolled in this study (M age for the 875 boys: 11.2 years; range, 7.6-14.0; $\mathrm{M}$ age for the 914 girls: 11.2 years; range, 9.4-13.6). All adopted and halfsiblings were excluded.

\section{Procedure}

As part of the diagnostic procedure, parents completed various questionnaires at the time of intake. One of these questionnaires was the BVT (Dutch questionnaire on biodemographic variables (Cohen-Kettenis \& van Goozen, 1997), which contains, among other things, questions about the family composition, including date of birth of the other siblings and whether the siblings were full biological siblings or half-siblings, and whether there were adopted children in their family. These data and some data from the medical files (e.g., diagnosis, age, sex) were used for the study. All probands had the Dutch nationality. The study was approved by the Ethics committee of the VU University Hospital.

For calculations on the sibling sex ratio and birth order, excepting Berglin's Index, only probands with at least one sibling were included. For calculations on fraternal and sororal birth order, only probands with at least one brother or sister, respectively, were included.

\section{Statistical Analysis}

In order to assess the sibling sex ratio, we compared the total number of siblings of each group of subjects with the "secondary sex ratio," which is the ratio of male live births to female live births. The proportion of male births was compared with the expected population mean of 0.515 (106:100 expressed in decimals for calculation purposes equals $106 /(100+106)=0.515)$ (Chahnazarian, 1988) by using the $z$-approximation to the binomial test. For comparisons of sibling sex ratios between the observed research groups, the Fisher's Exact Test was used. The variation between couples in the probability of producing male offspring is very slight (James, 1987). Thus, any effects of familial clustering within the examined samples would be tiny, and any potential violation of the assumption of independence of observations caused by the presence of multiple siblings from the same family would have a negligible effect on the $p$ values produced by these Fisher's Exact Tests.

In order to assess birth order, we recorded the numbers of older brothers, older sisters, younger brothers, and younger sisters, as well as the total number of siblings of each subject. The means and SDs of the total number of siblings, older brothers, older sisters, younger brothers, and younger sisters were calculated. Means were compared using independent samples $t$-tests.

Slater's Index expresses birth order as a quantity between 0 and 1 , where 0 means the proband is the first born child and 1 means the proband is the last born. The expected value for Slater's Index for samples randomly drawn from a stable population is 0.50 (Blanchard \& Sheridan, 1992). To calculate whether the birth order of a group was significantly early or late, it was compared with the Slater's Index of the appropriate control group. Because Slater's Index cannot be calculated for singletons, Berglin's Index was used as an alternative relativistic measure of birth order. For calculating Berglin's Index, 0.5 is added to the number of older siblings, and 1.0 is added to the total number of siblings.

\section{Results}

Of the female probands in the gender dysphoric group, 28 (29.5\%) of the total of 95 were only children compared with 116 $(12.7 \%)$ of the 914 control females. This difference was statistically significant, $\chi^{2}(1)=19.81, p<.001$. Sixteen $(17.0 \%)$ of the 94 gender dysphoric boys were only children whereas in the control group 107 (12.2\%) of the 875 boys were only children. This difference was not significant, $\chi^{2}(1)=1.76$. 
Table 1 Sibling sex ratio in gender dysphoric adolescents and control subjects

\begin{tabular}{|c|c|c|c|c|c|c|}
\hline Group & Probands & Brothers & Sisters & $\begin{array}{l}\text { Overall } \\
\text { sex ratio }\end{array}$ & $\begin{array}{l}\text { Sex ratio } \\
\text { older sibs }\end{array}$ & $\begin{array}{l}\text { Sex ratio } \\
\text { younger sibs }\end{array}$ \\
\hline GD boys & 94 & $89(\mathrm{OB} 48$, YB 41) & $37(\mathrm{OS} \mathrm{16}, \mathrm{YS} 21)$ & $241: 100 * *$ & $300: 100 * *$ & $195: 100^{*}$ \\
\hline GD girls & 95 & 43 (OB 24, YB 19) & $56(\mathrm{OS} 22, \mathrm{YS} 34)$ & $77: 100$ & 109:100 & $56: 100$ \\
\hline Control boys & 875 & 593 (OB 294, YB 299) & $598(\mathrm{OS} \mathrm{284,} \mathrm{YS} \mathrm{314)}$ & $99: 100$ & 104:100 & $95: 100$ \\
\hline Control girls & 914 & 634 (OB 328, YB 306) & $642(\mathrm{OS} \mathrm{302,} \mathrm{YS} \mathrm{340)}$ & 99:100 & 109:100 & $90: 100$ \\
\hline
\end{tabular}

$G D$ gender dysphoric, $O B$ older brothers, $Y B$ younger brothers, $O S$ older sisters, $Y S$ younger sisters

$* p<.05, * * p<.001$ for GD groups compared to the control groups per sex

\section{Sibling Sex Ratio}

Table 1 shows the number of probands in each group, their collective number of brothers and sisters, and the sex ratios. The sibling sex ratio for the gender dysphoric boys (241:100) was significantly higher than the expected population value (106:100), $z=4.31, p<$.001. It was also higher than the value for the control boys (99:100) in a direct between-groups comparison (Fisher's Exact Test: $p<.001$ ). Especially the sex ratio of the older siblings for the gender dysphoric boys was significantly higher than the older sibling sex ratio of the control boys, 300:100 versus 104:100, respectively (Fisher's Exact Test: $p<.001$ ). The ratio of younger siblings for the gender dysphoric boys was less elevated but still significantly higher than the ratio for the younger siblings of the control males, 195:100 versus 95:100 (Fisher's Exact Test, $p<.05$ ).

Although the overall sibling sex ratio for the gender dysphoric females was lower than the expected population value, this difference was not significant. When compared to the expected ratio of 0.515 , the sibling sex ratio for the younger siblings was significantly lower $(z=-2.28, p=.023)$. However, the younger sibling sex ratio of the control group was also significantly lower when compared to the expected ratio of $0.515(z=-2.10, p=.036)$. When we compared the younger sibling sex ratio of the gender dysphoric girls to the ratio of the control girls, no significant difference between the two ratios was found.

\section{Birth Order}

The results for the four relativized birth order indices (Slater's Index, Berglin's Index, and the fraternal and sororal birth order indices based on Slater's Index) are shown in Tables 2 and 3. None of the eight between-groups comparisons (GID boys vs. control boys, and GID girls vs. controls girls) was statistically significant (all $p s>.25$ ). It should be noted that the purpose of these relativized measures is primarily to control for differences in family size between compared groups, and that they do not necessarily provide the most powerful tests of between-groups differences related to birth order or fraternal birth order.

Quite different results were obtained for (untransformed) numbers of total siblings, older brothers, older sisters, younger
Table 2 Birth order in gender dysphoric adolescent and control subjects using Slater's and Berglin's index

\begin{tabular}{lrllllll}
\hline Group & $n$ & \multicolumn{2}{c}{ Slater's index } & $n$ & \multicolumn{2}{c}{ Berglin's index } \\
\cline { 3 - 4 } & & $M$ & $S D$ & & $M$ & $S D$ \\
\hline Gender dysphoric boys & 78 & 0.52 & .46 & 94 & 0.50 & .24 \\
Control boys & 768 & 0.47 & .46 & 875 & 0.49 & .24 \\
Gender dysphoric girls & 67 & 0.48 & .46 & 95 & 0.48 & .21 \\
Control girls & 798 & 0.47 & .45 & 914 & 0.49 & .24 \\
\hline
\end{tabular}

Table 3 Fraternal and sororal birth order for all four groups

\begin{tabular}{lrllllll}
\hline Group & $n$ & \multicolumn{2}{l}{ FBO } & & $n$ & \multicolumn{2}{l}{ SBO } \\
\cline { 3 - 4 } & & $M$ & $S D$ & & & $M$ & $S D$ \\
\hline Gender dysphoric boys & 67 & 0.53 & .47 & 35 & 0.44 & .49 \\
Control boys & 456 & 0.48 & .48 & 475 & 0.47 & .48 \\
Gender dysphoric girls & 36 & 0.56 & .48 & 44 & 0.38 & .46 \\
Control girls & 494 & 0.49 & .48 & 492 & 0.47 & .47 \\
\hline
\end{tabular}

$F B O$ fraternal birth order, $S B O$ sororal birth order

brothers, and younger sisters. The means of these variables are shown in Table 4. The gender dysphoric boys had significantly more older brothers than the control boys, but significantly fewer older sisters and younger sisters. Gender dysphoric boys also tended to have more younger brothers than the control boys, but this difference did not reach statistical significance. The two male groups were virtually identical with regard to their total numbers of siblings.

The female groups, unlike the male groups, did show a significant difference in family size: The gender dysphoric girls had significantly fewer total siblings than the control girls. This trend was apparent in each sibling category but reached statistical significance in separate comparisons only for the category of younger brothers.

Several previous studies have used logistic regression to calculate how much each older brother increases the odds of homosexuality in later-born males. It was reasonable to assume that all or nearly all of the early-onset gender dysphoric boys in this study were, or would be, homosexual, and that nearly all of the control boys were, or would be, heterosexual; therefore, a quantitative comparison of the present study with previous 
Table 4 Means and standard deviations of GD patients' and the controls' total number of siblings, and numbers of older brothers, older sisters, younger brothers, and younger sisters

\begin{tabular}{|c|c|c|c|c|c|c|c|c|}
\hline & \multirow{2}{*}{$\begin{array}{l}\text { GD boys } \\
(n=94) \\
\text { Mean }(S D)\end{array}$} & \multirow{2}{*}{$\begin{array}{l}\text { Control boys } \\
(n=875) \\
\text { Mean }(S D)\end{array}$} & \multicolumn{2}{|c|}{ Comparison test $\mathrm{t}^{\mathrm{a}}$} & \multirow{2}{*}{$\begin{array}{l}\text { GD girls } \\
(n=95) \\
\text { Mean }(S D)\end{array}$} & \multirow{2}{*}{$\begin{array}{l}\text { Control girls } \\
(n=914) \\
\text { Mean }(S D)\end{array}$} & \multicolumn{2}{|c|}{ Comparison test $\mathrm{t}^{\mathrm{a}}$} \\
\hline & & & $t(d f)$ & $p$ & & & $t(d f)$ & $p$ \\
\hline All siblings & $1.34(0.87)$ & $1.36(0.96)$ & $0.20(967)$ & ns & $1.04(0.89)$ & $1.40(0.95)$ & $3.49(1007)$ & .001 \\
\hline Older brothers & $0.51(0.70)$ & $0.34(0.62)$ & $-2.33(109)$ & .022 & $0.25(0.48)$ & $0.36(0.63)$ & $1.98(130)$ & ns \\
\hline Older sisters & $0.17(0.38)$ & $0.32(0.58)$ & $3.54(144)$ & .001 & $0.23(0.49)$ & $0.33(0.57)$ & $1.83(122)$ & ns \\
\hline Younger brothers & $0.44(0.63)$ & $0.34(0.59)$ & $-1.47(967)$ & ns & $0.20(0.45)$ & $0.33(0.56)$ & $2.70(126)$ & .008 \\
\hline Younger sisters & $0.22(0.44)$ & $0.36(0.59)$ & $2.71(131)$ & .008 & $0.36(0.58)$ & $0.37(0.60)$ & $0.22(1007)$ & ns \\
\hline
\end{tabular}

a The same number of subjects was used in each comparison for males and each comparison for females. Degrees of freedom $(d f)$ vary, however, because alternative versions of the $t$-tests were used, depending on whether Levene's Test for Equality of Variances justified the assumption of equal variances. All $p$-values are two-tailed

studies would be informative. As in previous research, separate logistic regression analyses were carried out for the male and female probands. The criterion variable was group membership (control $=0$ and gender dysphoric $=1$ ), and the predictors were the proband's numbers of older brothers, older sisters, younger brothers, and younger sisters. Because all the predictors were evaluated simultaneously, there was only one regression analysis for the boys and one for the girls.

The results are shown in Table 5. The logistic regression analysis for the males produced a pattern of results generally similar to that obtained with the (univariate) $t$-tests. Older brothers increased the odds that a proband would belong to the gender dysphoric/homosexual group, whereas older sisters and younger sisters decreased the odds. The odds ratio for older brothers was 1.47 , which means that each older brother increased the odds of homosexuality by $47 \%$.

The regression analysis for girls reinforced the impression that the gender dysphoric females came from smaller families than the control females. Every class of sibling except younger sisters significantly reduced the odds that a proband would

Table 5 Logistic regression analyses of group membership/sexual orientation on the four classes of siblings

\begin{tabular}{lrlllll}
\hline Predictor & \multicolumn{1}{l}{$B$} & $S E$ & Wald & $d f$ & $p$ & Odds ratio \\
\hline $\begin{array}{l}\text { Analysis for males } \\
\text { Older brothers }\end{array}$ & 0.38 & 0.16 & 5.40 & 1 & .020 & 1.47 \\
Older sisters & -0.66 & 0.27 & 6.09 & 1 & .014 & 0.52 \\
Younger brothers & 0.24 & 0.18 & 1.75 & 1 & $\mathrm{~ns}$ & 1.27 \\
Younger sisters & -0.47 & 0.24 & 3.89 & 1 & .049 & 0.62 \\
Analysis for females & & & & & & \\
Older brothers & -0.50 & 0.22 & 5.13 & 1 & .024 & 0.61 \\
Older sisters & -0.52 & 0.23 & 5.06 & 1 & .025 & 0.59 \\
Younger brothers & -0.76 & 0.25 & 8.81 & 1 & .003 & 0.47 \\
Younger sisters & -0.24 & 0.20 & 1.46 & 1 & $\mathrm{~ns}$ & 0.79 \\
\hline
\end{tabular}

belong to the gender dysphoric group, and even the results for younger sisters were in the same direction.

A final analysis compared mean sibship size in all four groups. (The four relevant means are shown in the first row of Table 4.) A Scheffé multiple-range test at the $p<.05$ level showed that the gender dysphoric girls had fewer siblings than the other three groups, which did not differ from each other.

\section{Discussion}

In this study, the most notable finding was the striking excess of (primarily older) brothers in the gender dysphoric males. The sibling sex ratio of the gender dysphoric boys was very high (241 brothers per 100 sisters) compared with the expected ratio of 106 male live births per 100 female live births. The excess of brothers was more extreme among the probands' older siblings (300:100) than among their younger siblings (195:100). Between-groups comparisons showed that the gender dysphoric boys had significantly more older brothers, and significantly fewer older sisters and younger sisters, than did the control boys. In contrast, there were almost no differences in sibship parameters for the female groups. The one exception was family size; the gender dysphoric girls had significantly fewer total siblings than did the control girls. This trend was apparent in each sibling category but reached statistical significance in separate comparisons only for the category of younger brothers. The results for the male probands were consistent with prior speculations that a high fraternal birth order (i.e., an excess of older brothers) is found in all homosexual male groups, but an elevated sibling sex ratio (usually caused by an additional, smaller excess of younger brothers) is characteristic of gender dysphoric homosexual males.

It is noteworthy that the gender dysphoric boys' extremely high ratio of older brothers to older sisters did not translate into an unusually high odds ratio as estimated by logistic regression. In this study, each older brother increased the odds that a boy would 
belong to the gender dysphoric group rather than the control group by $47 \%$. In previous investigations, older brothers increased the odds that an adult male subject would belong to the homosexual study group rather than the heterosexual study group by similar odds. Blanchard and Bogaert (1996), for example, calculated that each additional older brother increased a male's odds of homosexuality by $33 \%$. Subsequent studies have produced estimates with the same order of magnitude, for example, $48 \%$ for Blanchard, Zucker, Siegelman, Dickey, and Klassen (1998) and 28\% for Ellis and Blanchard (2001). Green (2000) found that each older brother increased the odds that a male transsexual is homosexual by $40 \%$, and VanderLaan and Vasey (2011) found that that each additional older brother increased the chances of developing male homosexuality in Samoa by approximately $34 \%$.

Our finding of the high number of brothers in the gender dysphoric boys group was in line with previous reports. In the Blanchard et al. (1996) study, the observed sibling sex ratio was 134:100 in an androphilic subgroup of gender dysphoric adolescent and adult males (15-57 years). Zucker et al. (1997) found a similar sibling sex ratio of 131:100 in a group of gender dysphoric boys (3-12 years). It is noteworthy, though, that the sex ratio found in our study was much higher than what was found in Blanchard et al.'s and Zucker et al.'s studies. For the Zucker et al. study, the lower ratio could be explained by the young age of their probands, as compared to the adolescents of our study. Only a small proportion of children fulfilling DSMIV-TR criteria of GID will have persisting gender dysphoria after puberty (Wallien \& Cohen-Kettenis, 2008). It may, therefore, be that a high sibling sex ratio is only something to be found in more severe gender dysphoric groups. Since our group was comparable to the group of the Blanchard et al. study, it remains unclear why there was such a difference between the two sibling sex ratios.

It also remains unknown what underlying mechanism may be responsible for the increased sibling sex ratio in families of gender dysphoric males. A large epidemiological study from Denmark showed an increase in the probability of having a boy as a next child, if the first child was a boy. The probability even further increased with increasing numbers of preceding male offspring. It is thought that this phenomenon is due to "biological heterogeneity," meaning that some couples tend to have more male or more female offspring, and therefore the likelihood of having a boy is not a constant (Biggar, Wohlfahrt, Westergaard, \& Melbye, 1999). Whether factors responsible for "biological heterogeneity" are also implicated in the excess of brothers in families of male gender dysphorics should be further investigated.

James (2008) hypothesized the hormonal status of both parents at time of conception to be of great importance for the determination of the offspring's sex. According to his theory, high levels of testosterone in the father or estrogens in the mother at time of conception would result in an increased sex ratio or, in other words, an excess of boys. James' hypothesis only refers to the hormone status of either parent shortly before insemination. It is conceivable that the parental hormonal status prior to insemination not only influences the sex ratio of the offspring, but also the intrauterine sex steroid levels (at least in the mother). If that were true, the same atypical sex steroid levels (in the mother) that had been responsible for the enhanced rates of brothers in gender dysphoric boys might also contribute, during pregnancy, to the boys' gender dysphoria. There are indications that sex steroid levels and/or sex steroid receptor abnormalities are related to atypical gender identity. For instance, longer CAG repeats, which are certain nucleotide repeats in the androgen receptor gene, have been associated with $\mathrm{MtF}$ transsexualism. This polymorphism results in less effective testosterone signalling, which, in turn, may result in a less masculinized brain during fetal development (Hare et al., 2009). In FtMs, a functional single nucleotide polymorphism in the CYP17 gene was found to be statistically significantly associated with transsexualism (Bentz et al., 2008). The gain of function mutation associated with the FtM transsexualism resulted in elevated serum and tissue levels of both estrogens and testosterone. These elevated levels could also interfere with normal fetal brain development (Bentz et al., 2008). Structural brain differences in transsexual individuals have indeed been found, such as the sex reversal of cell numbers and volume of the bed nucleus of the stria terminalis (Kruijver et al., 2000; Zhou, Hofman, Gooren, \& Swaab, 1995) and, more recently, the sex reversal of the interstitial nuclei 3 and 4 of the hypothalamus (Garcia-Falgueras \& Swaab, 2008). Also, a functional magnetic resonance imaging (fMRI) study revealed a tendency of femalelike cerebral processing of visual erotic stimuli in male-tofemale transsexuals (Gizewski et al., 2009). Furthermore, a significant larger volume of gray matter in the right putamen in MtFs was found, as compared to control men (Luders et al., 2009). It is, therefore, conceivable that the same sex hormonal disturbances that are responsible for the high sibling sex ratio in $\mathrm{MtF}$ are also leading to the atypical brain development that has been found in transsexuals.

There is a theory that male homosexuality (androphilia) persists in human populations because the same genes that predispose to homosexuality in males increase fecundity in females (e.g., VanderLaan \& Vasey, 2011). Thus, the low fertility of homosexual males is offset by high fertility in their female relatives, and the relevant genes/alleles are passed along at a stable rate in the population. This theory predicts that male homosexuals should have more siblings than comparable male heterosexuals. Assuming that a high percentage of the gender dysphoric boys are or, as they grow older, will be attracted to males (de Vries, Steensma, Doreleijers \& Cohen-Kettenis, 2010; Wallien $\&$ Cohen-Kettenis, 2008) that theory is contradicted by our data.

In the gender dysphoric girls, we found an overall sibling sex ratio of 77:100, which is indicative of an excess of sisters. However, the small number of siblings was most likely the 
reason why this deviation from the expected $\mathrm{M}: \mathrm{F}$ ratio of 106:100 was not significant. This again is in line with previous findings (Blanchard \& Sheridan, 1992; Green, 2000). In the first study, the sibling sex ratio of 95:100 was in the expected direction, but did not reach significance. In the second study, Green found a significant excess of sisters in a group of FtMs. Enlarging the group of our gender dysphoric adolescent girls would likely result in a more robust sibling sex ratio favoring an excess of sisters. However, it is unlikely that the mechanisms underlying a decreased sibling sex ratio and the development of gender dysphoria in girls are the same mechanisms hypothesized for boys.

Noteworthy was our finding that $29 \%$ of the gender dysphoric girls were singletons. It seems improbable that having a gender dysphoric daughter would in itself be a reason for having only one child. In the Netherlands, the mean age difference between two successive siblings is approximately 1.5-2 years. As the first signs of a gender dysphoria may become manifest around the age of 3 years, parents would already have chosen to have a second child before becoming aware of their daughter's gender dysphoria. Another reason for having no other children could be that the parents have fertility problems. It may be relevant here that Ellis and Blanchard (2001) found that mothers of homosexual females reported a higher proportion of pregnancies terminating before 6 months than did mothers of heterosexual females, heterosexual males, or homosexual males.

James (1985) found that subfertile females, treated with gonadotrophins to induce ovulation, have an excess of females among the offspring. He hypothesized the high levels of gonadotrophins to be responsible for the low sex ratio in the offspring. If ovulation in subfertile women is not hormonally induced, the sex ratio of offspring after artificial insemination is not as low as it would be after a hormonally induced ovulation. So it seems that subfertilility in itself does not lead to a decreased sex ratio of the offspring. However, we did not find indications in the medical records of our probands confirming possible fertility problems of either parent.

In contrast to the studies of Blanchard et al. (1996) and Zucker et al. (1997), we did not find any birth order effect in our population, when that parameter was quantified with either Slater's or Berglin's Index. However, we did find a significantly higher mean number of older brothers for the gender dysphoric boys when compared with the control boys. Blanchard and Klassen (1997) proposed the so-called "maternal immunization theory" as an explanation for the often found birth order effect among homosexuals. This theory, which has been challenged by some (Gooren, 2006), proposes that there are feminizing antibodies produced by the mother against foreign antigens, in this case antigens present on the Y-chromosome, more specifically the Y-linked minor histocompatibility antigens. These antibodies are believed to have a feminizing effect on the brains of successive male offspring, which may interfere with sexual orientation development. Blanchard (2004) reviewed the possible candidate proteins for the maternal immune hypothesis. The male Y-chromosome encodes at least 27 distinct proteins or protein families that are only produced by males and can stimulate immune responses in females (Skaletsky et al., 2003). One of these proteins is the protocadherin 11 Y-linked. The Y-linked genes of this protein are primarily expressed in the brain and only in small amounts in the testis (Blanco, Sargent, Boucher, Mitchell, \& Nabeel, 2000). This cell surface protein is involved in cell-cell interactions during embryonic brain development. It has been suggested that Y-chromosome genes could be related to sex-dimorphic differences in behavior and cognition (Blanco et al., 2000). Overexpression of the protocadherin $11 \mathrm{X}$-Y-linked gene could account for some abnormalities found in the brains of individuals with Klinefelter's syndrome (Ross et al., 2006). Although this gene and the accompanying protein may be good candidates for the brain alterations that possibly result in gender dysphoria, it remains unknown if this protein is able to create an immunological reaction of the mother. Although only the mean number of older brothers of the gender dysphoric boys was significantly higher when compared to the control group, there also seems to be a tendency for the gender dysphoric boys to have more younger brothers. The fact that the gender dysphoric group also had more younger brothers (without gender dysphoria) is not in line with what one would expect on the basis of the above mentioned maternal immunization theory.

Although we did not find a birth order effect or a deviation of the sibling sex ratio in the gender dysphoric females, we did find an increased sibling sex ratio and a significantly increased number of older brothers in the gender dysphoric boys. These results emphasize the consistency of the increased sibling sex ratio findings in gender dysphoric males. Future research aiming at potential etiological aspects, such as possible genetic factors, particularly variations in genes involved in the sex steroid genesis and sex steroid signalling (e.g., sex steroid receptors), may shed more light on both the development of gender dysphoria and the increased sibling sex ratio found in gender dysphoric boys. It would also be of great interest to look at the gender development of children of mothers with known intrauterine sex steroid levels during pregnancy.

Acknowledgments The authors would like to thank Ferring Pharmaceuticals for their independent research grant. They also would like to thank the Editor for his help and advice on the statistical analysis. D. R. Veensta is greatly acknowledged for providing the data of the control subjects. The work of Richard van Elmpt and Renske Konings, medical students of the medical faculty of the VU University Medical Centre, is greatly appreciated.

Open Access This article is distributed under the terms of the Creative Commons Attribution Noncommercial License which permits any noncommercial use, distribution, and reproduction in any medium, provided the original author(s) and source are credited. 


\section{References}

American Psychiatric Association. (2000). Diagnostic and statistical manual of mental disorders (4th ed., text revision). Washington, DC: Author.

Bentz, E. K., Hefler, L. A., Kaufmann, U., Huber, J. C., Kolbus, A., \& Tempfer, C. B. (2008). A polymorphism of the CYP17 gene related to sex steroid metabolism is associated with female-to-male but not male-to-female transsexualism. Fertility and Sterility, 90, 56-59.

Biggar, R. J., Wohlfahrt, J., Westergaard, T., \& Melbye, M. (1999). Sex ratios, family size, and birth order. American Journal of Epidemiology, 150, 957-962.

Blanchard, R. (1997). Birth order and sibling sex ratio in homosexual versus heterosexual males and females. Annual Review of Sex Research, 8, 27-67.

Blanchard, R. (2001). Fraternal birth order and the maternal immune hypothesis of male homosexuality. Hormones and Behavior, 40, $105-114$.

Blanchard, R. (2004). Quantitative and theoretical analyses of the relation between older brothers and homosexuality in men. Journal of Theoretical Biology, 230, 173-187.

Blanchard, R. (2008). Review and theory of handedness, birth order, and homosexuality in men. Laterality, 13, 51-70.

Blanchard, R., \& Bogaert, A. F. (1996). Homosexuality in men and number of older brothers. American Journal of Psychiatry, 153, 27-31.

Blanchard, R., \& Klassen, P. (1997). H-Y antigen and homosexuality in men. Journal of Theoretical Biology, 185, 373-378.

Blanchard, R., \& Lippa, R. A. (2007). Birth order, sibling sex ratio, handedness, and sexual orientation of male and female participants in a BBC internet research project. Archives of Sexual Behavior, $36,163-176$.

Blanchard, R., \& Sheridan, P. M. (1992). Sibship size, sibling sex ratio, birth order, and parental age in homosexual and non-homosexual gender dysphorics. Journal of Nervous and Mental Disease, 180, 40-47.

Blanchard, R., Zucker, K. J., Cavacas, A., Allin, S., Bradley, S. J., \& Schachter, D. C. (2002). Fraternal birth order and birth weight in probably prehomosexual feminine boys. Hormones and Behavior, 41, 321-327.

Blanchard, R., Zucker, K. J., Cohen-Kettenis, P. T., Gooren, L. J., \& Bailey, J. M. (1996). Birth order and sibling sex ratio in two samples of Dutch gender-dysphoric homosexual males. Archives of Sexual Behavior, 25, 495-514.

Blanchard, R., Zucker, K. J., Siegelman, M., Dickey, R., \& Klassen, P. (1998). The relation of birth order to sexual orientation in men and women. Journal of Biosocial Science, 30, 511-519.

Blanco, P., Sargent, C. A., Boucher, C. A., Mitchell, M., \& Nabeel, A. A. (2000). Conservation of PCDHX in mammals: Expression of human X/Y genes predominantly in brain. Mammalian Genome, $11,906-914$.

Bogaert, A. F. (2006). Biological versus nonbiological older brothers and men's sexual orientation. Proceeding of the National Academy of Sciences of the United States of America, 103, 10771-10774.

Bogaert, A. F., \& Cairney, J. (2004). The interaction of birth order and parental age on sexual orientation: An examination in two samples. Journal of Biosocial Science, 36, 19-37.

Bogaert, A. F., \& Liu, J. (2006). Birth order and sexual orientation in men: Evidence for two independent interactions. Journal of Biosocial Science, 38, 811-819.

Chahnazarian, A. (1988). Determinants of the sex ratio at birth: Review of recent literature. Social Biology, 35, 214-235.

Cohen-Kettenis, P. T., \& van Goozen, S. H. (1997). Sex reassignment of adolescent transsexuals: A follow-up study. Journal of the American Academy of Child and Adolescent Psychiatry, 36, 263-271. de Vries, A. L. C., Steensma, T. D., Doreleijers, T. A. H., \& CohenKettenis, P. T. (2010). Puberty suppression in adolescents with gender identity disorder: A prospective follow-up study. Journal of Sexual Medicine, doi:10.1111/j.1743-6109.2010.01943.x.

De Winter, A. F., Oldehinkel, A. J., Veenstra, R., Brunnekreef, J. A., Verhulst, F. C., \& Ormel, J. (2005). Evaluation of non-response bias in mental health determinants and outcomes in a large sample of pre-adolescents. European Journal of Epidemiology, 20, 173-181.

Ellis, L., \& Blanchard, R. (2001). Birth order, sibling sex ratio, and maternal miscarriages in homosexual and heterosexual men and women. Personality and Individual Differences, 30, 543-552.

Garcia-Falgueras, A., \& Swaab, D. F. (2008). A sex difference in the hypothalamic uncinate nucleus: Relationship to gender identity. Brain, 131, 3132-3146.

Gizewski, E. R., Krause, E., Schlamann, M., Happich, F., Ladd, M. E., Forsting, M., \& Senf, W. (2009). Specific cerebral activation due to visual erotic stimuli in male-to-female transsexuals compared with male and female controls: An fMRI study. Journal of Sexual Medicine, 6, 440-448.

Gomez-Gil, E., Esteva, I., Carrasco, R., Almaraz, M. C., Pasaro, E., Salamero, M., \& Guillamon, A. (2011). Birth order and ratio of brothers to sisters in Spanish transsexuals. Archives of Sexual Behavior, 40, 505-510.

Gooren, L. (2006). The biology of human psychosexual differentiation. Hormones and Behavior, 50, 589-601.

Green, R. (2000). Birth order and ratio of brothers to sisters in transsexuals. Psychological Medicine, 30, 789-795.

Hare, L., Bernard, P., Sánchez, F. J., Baird, P. N., Vilain, E., Kennedy, T., \& Harley, V. R. (2009). Androgen receptor repeat length polymorphism associated with male-to-female transsexualism. Biological Psychiatry, 65, 93-96.

James, W. H. (1985). The sex ratio of infants born after hormonal induction of ovulation. British Journal of Obstetrics and Gynaecology, 92, 299-301.

James, W. H. (1987). The human sex ratio: Part 1. A review of the literature. Human Biology, 59, 721-752.

James, W. H. (2008). Evidence that mammalian sex ratios at birth are partially controlled by parental hormone levels around the time of conception. Journal of Endocrinology, 198, 3-15.

Kruijver, F. P., Zhou, J. N., Pool, C. W., Hofman, M. A., Gooren, L. J., \& Swaab, D. F. (2000). Male-to-female transsexuals have female neuron numbers in a limbic nucleus. Journal of Clinical Endocrinology and Metabolism, 85, 2034-2041.

Lang, T. (1960). Die Homosexualitat als genetisches Problem. Acta Geneticae Medicae et Gemellologiae, 9, 370-381.

Luders, E., Sánchez, F. J., Gaser, C., Toga, A. W., Narr, K. L., Hamilton, L. S., \& Vilain, E. (2009). Regional gray matter variation in maleto-female transsexualism. Neuroimage, 46, 904-907.

Poasa, K. H., Blanchard, R., \& Zucker, K. J. (2004). Birth order in transgendered males from Polynesia: A quantitative study of Samoan fa'afāfine. Journal of Sex and Marital Therapy, 30, 13-23.

Ross, N. L., Wadekar, R., Lopes, A., Dagnall, A., Close, J., Delisi, L. E., \& Crow, T. J. (2006). Methylation of two Homo sapiens-specific $\mathrm{X}$-Y homologous genes in Klinefelter's syndrome (XXY). American Journal of Medical Genetics Part B Neuropsychiatric Genetics, 141B, 544-548.

Skaletsky, H., Kuroda-Kawaguchi, T., Minx, P. J., Cordum, H. S., Hillier, L., Brown, L. G., et al. (2003). The male-specific region of the human Y chromosome is a mosaic of discrete sequence classes. Nature, 423, 825-837.

Slater, E. (1958). The sibs and children of homosexuals. In D. R. Smith \& W. M. Davidson (Eds.), Symposium on nuclear sex (pp. 79-83). London: Heinemann. 
Smith, Y. L., van Goozen, S. H., Kuiper, A. J., \& Cohen-Kettenis, P. T. (2005). Transsexual subtypes: Clinical and theoretical significance. Psychiatry Research, 137, 151-160.

Tsoi, W. F., Kok, L. P., \& Long, F. Y. (1977). Male transsexualism in Singapore: A description of 56 cases. British Journal of Psychiatry, 131, 405-409.

VanderLaan, D. P., \& Vasey, P. L. (2011). Male sexual orientation in independent Samoa: Evidence for fraternal birth order and maternal fecundity effects. Archives of Sexual Behavior, 40, 495-503.

Vasey, P. L., \& VanderLaan, D. P. (2007). Birth order and male androphilia in Samoan fa' afafine. Proceedings of the Royal Society of Biological Sciences, 274, 1437-1442.

Wallien, M. S., \& Cohen-Kettenis, P. T. (2008). Psychosexual outcome of gender-dysphoric children. Journal of the American Academy of Child and Adolescent Psychiatry, 47, 1413-1423.
Zhou, J. N., Hofman, M. A., Gooren, L. J., \& Swaab, D. F. (1995). A sex difference in the human brain and its relation to transsexuality. Nature, 378, 68-70.

Zucker, K. J., Blanchard, R., Kim, T. S., Pae, C. U., \& Lee, C. (2007). Birth order and sibling sex ratio in homosexual transsexual South Korean men: Effects of the male-preference stopping rule. Psychiatry and Clinical Neuroscience, 61, 529-533.

Zucker, K. J., Green, R., Coates, S., Zuger, B., Cohen-Kettenis, P. T., Zecca, G. M.,...Blanchard, R. (1997). Sibling sex ratio of boys with gender identity disorder. Journal of Child Psychology and Psychiatry, 38, 543-551.

Zucker, K. J., Lightbody, S., Pecore, L., Bradley, S. J., \& Blanchard, R. (1998). Birth order in girls with gender identity disorder. European Child and Adolescent Psychiatry, 7, 30-35. 